BO YU, Ph.D. Candidate ${ }^{1}$

E-mail: clowyubo@126.com

YUREN CHEN, Ph.D. ${ }^{1}$

(Corresponding Author)

E-mail: chenyr@tongji.edu.cn

${ }^{1}$ Key Laboratory of Road and Traffic Engineering

of the Ministry of Education

Transportation Engineering School of Tongji University

4800 Cao'an Highway, Shanghai, 201804, China
Human - Transport Interaction

Original Scientific Paper

Submitted: 22 July 2016

Accepted: 15 Feb. 2017

\title{
DRIVING RHYTHM METHOD FOR DRIVING COMFORT ANALYSIS ON RURAL HIGHWAYS
}

\begin{abstract}
Driving comfort is of great significance for rural highways, since the variation characteristics of driving speed are comparatively complex on rural highways. Earlier studies about driving comfort were usually based on the actual geometric road alignments and automobiles, without considering the driver's visual perception. However, some scholars have shown that there is a discrepancy between actual and perceived geometric alignments, especially on rural highways. Moreover, few studies focus on rural highways. Therefore, in this paper the driver's visual lane model was established based on the Catmull-Rom spline, in order to describe the driver's visual perception of rural highways. The real vehicle experiment was conducted on $100 \mathrm{~km} \mathrm{ru}$ ral highways in Tibet. The driving rhythm was presented to signify the information during the driving process. Shape parameters of the driver's visual lane model were chosen as input variables to predict the driving rhythm by BP neural network. Wavelet transform was used to explore which part of the driving rhythm is related to the driving comfort. Then the probabilities of good, fair and bad driving comfort can be calculated by wavelets of the driving rhythm. This work not only provides a new perspective into driving comfort analysis and quantifies the driver's visual perception, but also pays attention to the unique characteristics of rural highways.
\end{abstract}

\section{KEY WORDS}

driving comfort; driver's visual lane model; driving rhythm; $B P$ neural network; wavelet transform;

\section{INTRODUCTION}

As functional requirements of roads and automobiles have advanced over the years, increasing attention has been paid to driving comfort. The driving comfort is of great significance, especially for rural highways. The variation characteristics of driving speed are comparatively complex on rural highways, not only because indices of horizontal, vertical and lateral alignments are relatively poor on rural highways, but also because in many cases there is uncoordinated combination of three-dimensional alignments, insufficient sight distance and so on. These cause a large deviation between geometric alignment information perceived by drivers and actual alignment indices [1]. Accordingly, the drivers cannot accurately perceive the information provided by road environment, resulting in discomfort and even accidents. When drivers stay in a comfortable driving condition, the incidence of traffic accidents can be reduced. Compared with traffic safety, the driving comfort has higher demands on road conditions. When road conditions satisfy the requirement of driving comfort, traffic safety can also be improved. That is to say, good driving comfort offers a guarantee for traffic safety. All fatal crashes occurring on rural roads accounted for approximately $60 \%$ in OECD Member countries [2]. In Iran 70\% of the fatalities occurred on rural roads [3]. During the process of driving on rural highways, 9,704 traffic accidents occurred in China, accounting for $36.7 \%$ of the total number of accidents, which caused 14,014 casualties, with direct property loss of 47.1 million RMB in 2014 [4]. Therefore, the driving comfort on rural highways from driver's visual perception is a critical topic urgently in need of research.

Current studies on driving comfort are mainly from aspects of automobiles and road alignments. The driving comfort is one of the most critical factors to evaluate the automobile performance [5]. The aim of active suspension control is to improve the driving comfort and reduce the body acceleration [6]. Yang et al. [5] presented a new index called annoyance rate to indicate the quantitative correlation between objective methods and subjective comments. Els et al. [7] pointed out that for the objective measurements, the ISO 2631, BS 6841, Average Absorbed Power and VDI 2057 methods were used to specify and evaluate the driving comfort. Múčka and Granlund [8] put forward that the IRI (International Roughness Index) cannot reflect the differences in road roughness and the seat frequency-weighted acceleration is a parameter that better reflects the driving comfort. 
Regarding road alignments, numerous researchers have adopted a number of parameters for driving comfort analysis. From the horizontal alignment perspective, the driving comfort is generally analysed according to the calculation of the lateral force, mainly including the sideway force coefficient and lateral acceleration. If the sideway force coefficient is too large, the drivers cannot drive continuously and stably [9]. Awadallah [10] used the lateral acceleration to detect the discomfort speed on highways. From the point of view of the vertical alignment, vertical acceleration is a dominant factor [11], and vertical curvatures of highways should satisfy the demand of driving comfort [12]. Hamdar et al. [13] stated that the lane width of a roadway also greatly affects the comfort of drivers. In order to depict the driving comfort from three-dimensional geometry alignments, some scholars chose the lateral change of acceleration and acceleration noise as the evaluation indices. Baykal [14] and Yang et al. [15] pointed out that the lateral change of acceleration can combine curvature, ultra-high and longitudinal slope together, which directly affects the driving comfort on highways. Yu and Chen [16] employed the lateral change of acceleration to describe the driving comfort on urban roads. Acceleration noise is defined as the standard deviation of accelerations [17]. When acceleration noise levels increase, the driving comfort decreases [18]. It can be calculated as follows:

$$
\begin{aligned}
& e_{j}=\sqrt{\frac{1}{T} \int_{0}^{T}\left[a\left(t_{i}\right)-\bar{a}\right]^{2} d t} \\
& e=\sqrt{e_{1}^{2}+e_{2}^{2}+e_{3}^{2}}
\end{aligned}
$$

where: $e_{j}$ denotes acceleration noise on the plane $j$; $j=1,2,3$, which denote the horizontal, vertical and longitudinal plane, respectively; $T$ is the total travel time; $a\left(t_{i}\right)$ is the acceleration at time $t_{i} ; \bar{a}$ is the average acceleration; $e$ is acceleration noise. When $e>1.5 \mathrm{~m} / \mathrm{s}^{2}$, the driving comfort is bad; $e<0.7 \mathrm{~m} / \mathrm{s}^{2}$ means the driving comfort is good; $0.7 \mathrm{~m} / \mathrm{s}^{2} \leq e \leq 1.5 \mathrm{~m} / \mathrm{s}^{2}$ represents fairly good comfort.

Given the above, there is little attention paid to driver's visual perception for driving comfort analysis. However, it is a crucial factor for the driving comfort. The drivers obtain more than $80 \%$ of road information from their visual perceptions. Some studies identified that there is a discrepancy between actual and perceived information, since combined horizontal and vertical alignments can cause an erroneous perception of the horizontal curvature [19]. Hassan and Easa [20] examined the hypothesis that the driver's visual perception of the horizontal curvature is affected by the overlapping vertical alignment. Moreover, current studies mostly focus on highways and urban roads. Rural highways have distinctive characteristics, so separate studies need to be given. In this paper, the driver's visual lane model was established to describe the driver's visual perception. Then the driving rhythm on rural highways was analysed to represent the driving comfort during the driving process.

\section{REAL VEHICLE EXPERIMENT}

In order to fully understand the driving comfort on rural highways, a real vehicle experiment has been conducted. This experiment aimed to figure out the driver's visual perception characteristics on rural highways, as well as the corresponding driving rhythm. Fourteen experienced drivers were selected to conduct the real vehicle experiment and their ages ranged from 25 to 40, in order to avoid the influence of the driving skill and tension of novice drivers.

Specific test procedure is as follows: $100 \mathrm{~km}$ rural highways in Tibet with different road conditions and varied facility layouts were selected to complete this experiment. A vehicle data recorder (GARMIN GDR35) was used to complete the experiment, located in the line of sight of the driver. The recorder combined GPS with the driving video records perfectly and overcame the GPS signal interference to camera lens. So it can record the driving position, velocity, three-axis accelerations and videos perceived by the driver's vision simultaneously. The information recording interval is 1 second, the video resolution is 1,920 x 1,080 pixels, the frame rate is 30 frames/s, the camera lens focal length $f=2.0$, the horizontal view angle is $51.22225^{\circ}$ and the vertical view angle is $34.99839^{\circ}$. The driving position, velocity, acceleration and driver's visual images etc. recorded by GARMIN GDR35 were all stored in the AVI file. Therefore, software technology was needed to extract the data. A real vehicle test data processing system was specially developed. The video processing technique used in this experiment was on the basis of what Wang et al. [21] put forward.

In this research, vehicles need to stay in the free traffic flow condition in good weather, in order to fully understand the driving comfort on rural highways. The data from some road segments which have interferences of other vehicles should be excluded. Good climate refers to clean road surface regardless of snow, ice and fog, etc. Ultimately, 790 sets of samples are valid, which were extracted from $57 \mathrm{~km}$ road sections on rural highways.

\section{CALCULATION OF DRIVING RHYTHM}

\subsection{Description of driving rhythm}

Driving rhythm refers to the tempo at which the drivers perceive road conditions and then generate driving behaviour responses, namely, regular and rhythmic changes generated by combinative visual perception and physical sensation during the driving process. When drivers stay in a proper driving rhythm, driving comfort and safety can be guaranteed. 
Table 1 - Classification method of "music notes"

\begin{tabular}{|c|c|c|c|}
\hline$\sigma_{\sigma^{2} / L}^{\overline{\Delta V}}$ & $0 \sim 0.75$ & $0.75 \sim 1.75$ & $>1.75$ \\
\hline 0 & 1 & 1 & $\dot{1}$ \\
\hline $0 \sim 0.00095$ & 2 & 2 & $\dot{2}$ \\
\hline $0.00095 \sim 0.00124$ & 3 & 3 & $\dot{3}$ \\
\hline $0.00124 \sim 0.0028$ & 4 & 4 & $\dot{4}$ \\
\hline $0.0028 \sim 0.00513$ & 5 & 5 & $\dot{5}$ \\
\hline $0.00513 \sim 0.0132$ & 6 & 6 & $\dot{6}$ \\
\hline$>0.0132$ & $?$ & 7 & $\dot{7}$ \\
\hline
\end{tabular}

The expression of driving rhythm is shown in Figure 1. Each grid represents data of 1 second. Specifically, $V$ denotes the driving speed, and $\Delta V$ signifies the speed variation between adjacent time intervals. Four seconds is the safe upper limit for the drivers' responses to normal stimuli on the road [22], so four grids are regarded as a group to form a "music note". That is to say, the driving rhythm can be understood as music rhythm composed by "music notes". Table 1 demonstrates the concrete classification method of "music notes". The mean speed variation within four seconds is denoted by $\overline{\Delta V}$, which reflects the change value of driving speed. Besides, $\sigma^{2}$ and $L$ are the variance of speed changes in four seconds and the sum of driving speeds of each group (4s), respectively. $\sigma^{2}$ is divided by $L$ (referred to as $\sigma^{2} / L$ ), which indicates the change rate of driving speed. According to the cumulative frequency the distributions of these two characteristic variables $\overline{\Delta V}$ and $\sigma^{2} / L$, the classification of "music notes" can be obtained. "Music notes" are split into three distinct parts: "low pitch" (1, 2, 3, 4, 5, 6, ?) "middle pitch" $(1,2,3,4,5,6,7)$ and "high pitch" $(\dot{1}$, $\dot{2}, \dot{3}, \dot{4}, \dot{5}, \dot{6}, \dot{7})$.

\subsection{Prediction model of driving rhythm from driver's visual perception}

\subsubsection{Driver's visual lane model}

During the driving process, a "lane" exists in the driver's visual field all the time. Even if there are no lane markings on the road surface, the drivers are able to perceive the shape of a "lane" according to the specific situations and then determine their driving behaviours. In fact, this "lane" can be described as driver's visual lane model based on Catmull-Rom Spline [23]. Yu et al. [24] and Chen et al. [25] have verified that Catmull-Rom Spline is more efficient and precise than others for fitting the driver's visual lane.

The driver's visual lane model is shown in Figure 2. Taking the bottom-left corner of the driver's visual field as the origin, a coordinate system is established in which the units of $X$ axis and $Y$ axis are pixels. The left side lane marker of the visual lane can be fitted by Catmull-Rom Spline that uses $\left(P_{L 1}, P_{L 2}, P_{L 3}, P_{L 4}\right)$ as control points and the information of these four control points is represented by $\left(S_{L i}, X_{L i}, Y_{L i}\right)(i=1,2,3,4)$, where $S_{L i}$ is the cumulative length of the left side lane marker of the visual lane at $P_{L i}$ point (pixels), and $\left(X_{L i}, Y_{L i}\right)$ are image coordinates (pixels). Besides, $f_{L i}$ is the tangential angle of the visual left lane marker at each control

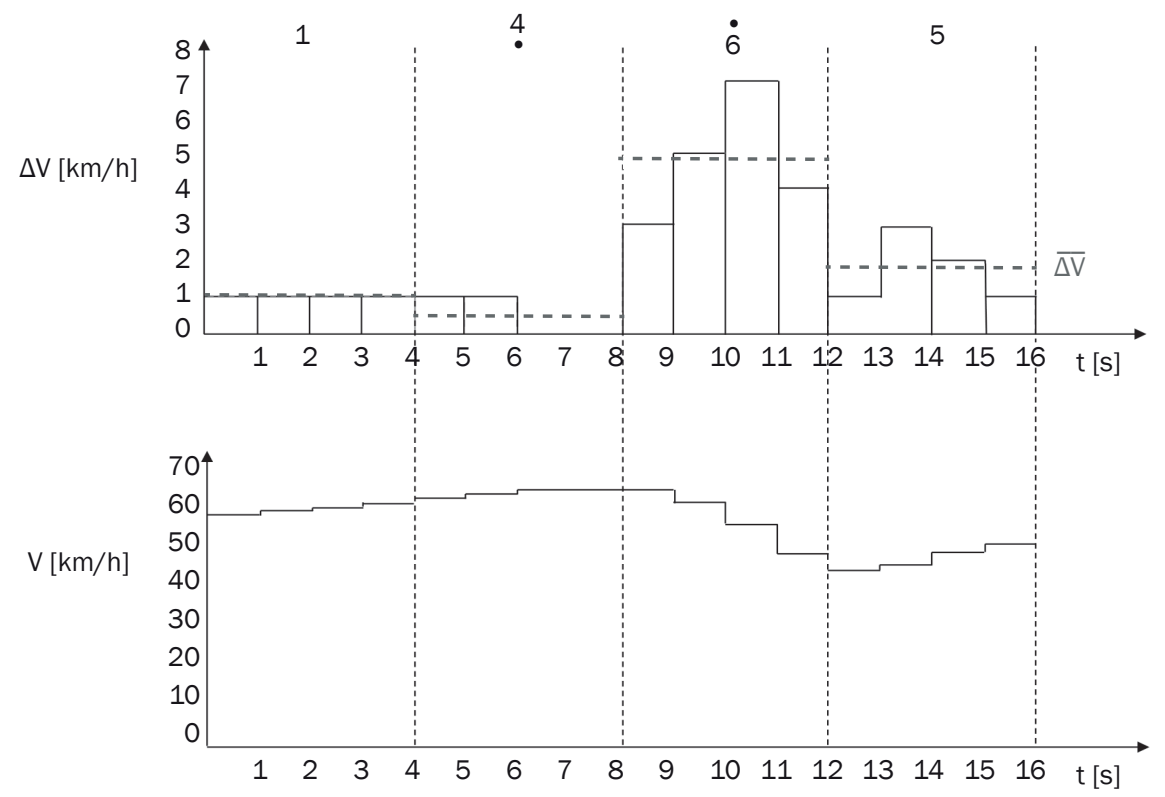

Figure 1 - Expression of driving rhythm and "music notes" 


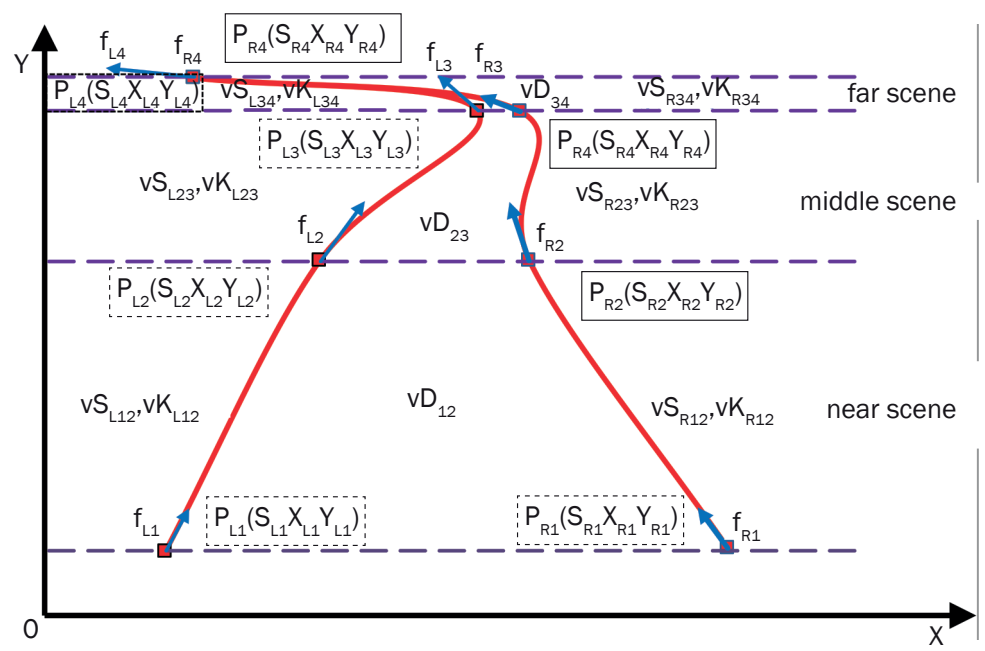

Figure 2 - Driver's visual lane model and shape parameters

point (radians). Likewise, using Catmull-Rom spline to fit the right side lane marker of the visual lane model, there will be four control points $\left(\mathrm{P}_{R 1}, \mathrm{P}_{R 2}, \mathrm{P}_{R 3}, \mathrm{P}_{R 4}\right)$, and $\left(S_{R i}, X_{R i}, Y_{R i}\right)(i=1,2,3,4)$ can denote the information of control points. Four horizontal lines that join the corresponding control points in the left and right side lane markers divide the visual lane in the driver's visual field into three distinct regions, namely, "near scene", "middle scene" and "far scene". $\left[v S_{L j(j+1)}, v K_{L j(j+1)}\right]$ $(j=1,2,3)$ are used to describe the visual curve length and curvature of the visual left side lane marker in three regions. Similarly, $\left[v S_{R j(j+1)}, v K_{R j(j+1)}\right]$ depict visual features of the visual right side lane marker in these three different areas. Meanwhile, the visual lane width in these sections can be denoted by $v D_{j(j+1)}$. Thus, $\left[v S_{L j(j+1)}, v K_{L j(j+1)}, v S_{R j(j+1)}, v K_{R j(j+1)}, v D_{j(j+1}\right]$ are called as shape parameters of visual lane model, which represent the length, curvature and width of a lane in the driver's vision. They can be calculated as follows:

$$
\begin{aligned}
& v S_{L j(j+1)}=S_{L(j+1)}-S_{L j} \\
& v K_{L j(j+1)}=\frac{f_{L(j+1)}-f_{L j}}{v S_{L j(j+1)}} \\
& v S_{R j(j+1)}=S_{R(j+1)}-S_{R j} \\
& v K_{R j(j+1)}=\frac{f_{R(j+1)}-f_{R j}}{v S_{R j(j+1)}} \\
& v D_{j(j+1)}=\frac{1}{2}\left[\sqrt{\left(X_{L j}-X_{R j}\right)^{2}+\left(Y_{L j}-Y_{R j}\right)^{2}}\right. \\
& \left.+\sqrt{\left(X_{L(j+1)}-X_{R(j+1)}\right)^{2}+\left(Y_{L(j+1)}-Y_{R(j+1)}\right)^{2}}\right]
\end{aligned}
$$

where: $j=1,2,3 ; v S_{L j(j+1)}$ denotes the visual curve length between control point $P_{L j}$ and $P_{L(j+1}$ (pixels); $v S_{R j(j+1)}$ denotes the visual curve length between control point $P_{R j}$ and $\mathrm{P}_{R(j+1)}$ (pixels); $v K_{L j(j+1)}$ denotes the visual curve curvature between control point $P_{L j}$ and $P_{L(j+1)}$, name$\mathrm{ly}$, the unit rate of change of tangential angle (radians); $v K_{R j(j+1)}$ denotes the visual curve curvature between control point $\mathrm{P}_{R j}$ and $\mathrm{P}_{R(j+1)}$ (radians); $v D_{j(j+1)}$ denotes the visual lane width (pixels); $f_{L j}, f_{R j}$ are the tangential angle at control point $\mathrm{P}_{L j}$ and $\mathrm{P}_{R j}$ (radians); $\mathrm{S}_{L i}, \mathrm{~S}_{R i}$ are the visual curve cumulative length at control point $P_{L j}$ and $\mathrm{P}_{R j}$ (pixels); $\left(\mathrm{X}_{L j}, \mathrm{Y}_{L j}\right),\left(\mathrm{X}_{R j}, \mathrm{Y}_{R j}\right)$ are the image coordinates of $\mathrm{P}_{L j}$ and $\mathrm{P}_{R j}$ (pixels).

\subsubsection{Prediction model of driving rhythm using BP neural network}

The Back-propagation Neural Network (BPNN) is a kind of multilayer feedforward neural network with the error back-propagation algorithm. Numerous experimental results have proven that BPNN has powerful self-learning and self-adaptation abilities, so it can obtain the mathematical mapping relationship between input and output variables. BPNN has been applied widely in the transportation engineering field, such as traffic flow forecasting [26], traffic accidents analysis [27], etc.

The entire BPNN consists of three kinds of layers: an input layer, a hidden layer and an output layer. Figure 3 demonstrates the typical structure of an $n-I-m$ BPNN, which has $n$ input variables, I nodes of hidden layer, and $m$ outputs. $X_{1}, X_{2}, \ldots, X_{n}$ are inputs of BPNN, and $Y_{1}, Y_{2}, \ldots, Y_{m}$ denote output variables. $w_{i j}$ and $w_{j k}$ are the input and output weight matrices, respectively.

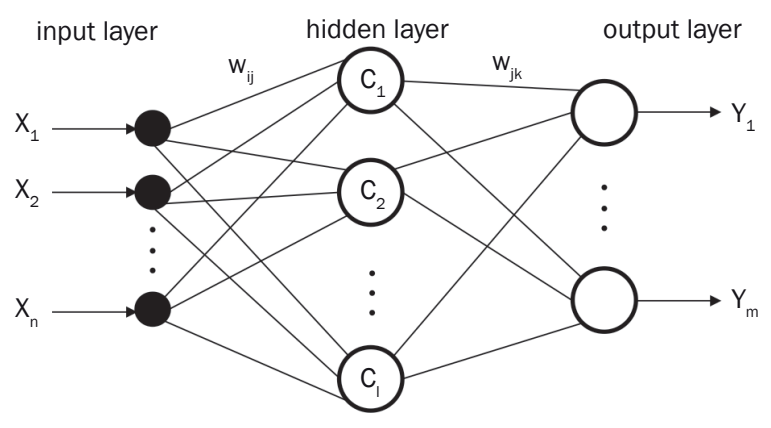

Figure 3 - Typical structure of BPNN 
To evaluate the performance of the BPNN with respect to the forecasting accuracy, various effective measures can be applied, such as the mean absolute percentage error and the mean square error.

$$
\begin{aligned}
& \text { MAPE }=\frac{1}{n} \sum_{t=1}^{n}\left|\frac{V_{t}-\widehat{V}_{t}}{V_{(t)}}\right| \\
& M S E=\frac{1}{n} \sum_{t=1}^{n}\left(V_{t}-\widehat{V}_{t}\right)^{2}
\end{aligned}
$$

where: MAPE denotes mean absolute percentage error; MSE denotes mean square error; $V_{t}$ is the actual value at time $t ; \hat{V} t$ is the forecast value at time $t$.

According to their visual perception, drivers determine the driving speed. Hence, shape parameters of the driver's visual lane model are used to predicate the driving speed, and then driving rhythm can be calculated according to Table 1.

There are 550 sets of data obtained from continuous road sections and used to establish the BPNN, and 50 samples from them have been randomly selected as test groups. Specifically, the input layer of

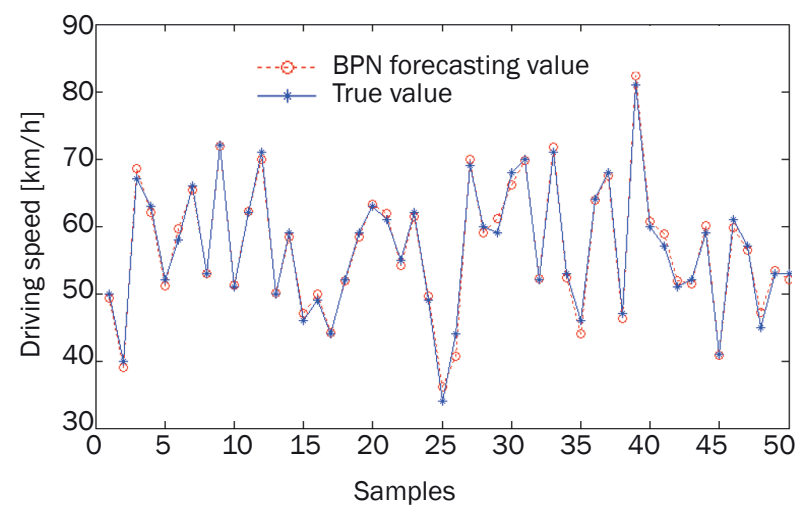

Figure 4 - Predicting outcomes of BPNN this BPNN has 16 neurons: differences of shape parameters between adjacent time intervals $\left[\Delta v S_{L j(j+1)}\right.$, $\left.\Delta v K_{L j(j+1)} \Delta v S_{R j(j+1)}, \Delta v K_{R j(j+1)}, \Delta v D_{j(j+1)}\right](j=1,2,3)$ and the driving speed of the previous second $V_{(t-1)}$, shown in Table 2. The output layer has one neuron representing the driving speed at this second $V_{t}$. As to the number of neurons of the hidden layer, the test result of eight neurons is the most optimal one, shown in Table 3. Both MAPE and MSE are less than others, which satisfy the precision demands for prediction assessment. Predicting outcomes of the BPNN have been illustrated in Figure 4.

\section{DRIVING COMFORT ANALYSIS ON RURAL HIGHWAYS}

\subsection{Wavelet transform}

Wavelet transform is a notable landmark in the progress of Fourier transform. As a mathematical tool, wavelets can be used to extract information from many different kinds of data, including audio signals and images. As with Fourier series analysis, wavelet transform is also based on a decomposition of a signal typically using an orthonormal family of basic functions, which are called wavelets. A set of wavelets will decompose the data without gaps or overlaps so that the decomposition process is mathematically reversible. Wavelet transform is capable of examining local data with adjustable window location and size, so it can provide multiple levels of details and approximations of the original signal. This advantage makes it suitable for time-frequency analysis [28]. Continuous wavelet transform is viewed as an effective method for both stationary and non-stationary signals. However, it contains a lot of redundant information and has slow computation speed [29]. In order to facilitate the

Table 2 - Input variables $\left(X_{1}, X_{2}, \ldots, X_{16}\right)$ of BPNN

\begin{tabular}{||c|c|c|c|c|c||}
\hline \hline Inputs & Mean & S.D. & Inputs & Mean & S.D. \\
\hline \hline$\Delta v S_{L 12}$ pixels) & -1.31 & 40.3 & $\Delta v S_{R 34}($ pixels $)$ & 0.125 & 55.8 \\
\hline$\Delta v S_{L 23}$ (pixels) & 0.07 & 40.1 & $\Delta v K_{R 12}$ & 0.000135 & 0.000250 \\
\hline$\Delta v S_{L 34}$ (pixels) & 0.19 & 48.2 & $\Delta v K_{R 23}$ & 0.00160 & 0.00268 \\
\hline$\Delta v K_{L 12}$ & 0.000253 & 0.000506 & $\Delta v K_{R 34}$ & 0.0354 & 0.00746 \\
\hline$\Delta v K_{L 23}$ & 0.00181 & 0.00268 & $\Delta v D_{12}($ pixels $)$ & 0.317 & 48.4 \\
\hline$\Delta v K_{L 34}$ & 0.00407 & 0.00889 & $\Delta v D_{23}$ (pixels) & 0.851 & 42.2 \\
\hline$\Delta v S_{R 12}$ (pixels) & -0.293 & 62.0 & $\Delta v D_{34}($ pixels $)$ & 0.851 & 19.4 \\
\hline$\Delta v S_{R 23}$ (pixels) & 0.441 & 50.5 & $V_{(t-1)}(\mathrm{km} / \mathrm{h})$ & 56.1 & 7.31 \\
\hline \hline
\end{tabular}

Table 3 - Prediction errors of driving speed with different numbers of nodes in the hidden layer

\begin{tabular}{|c|c|c|c|c|c|c|c||}
\hline Number of Nodes & 4 & 6 & 8 & 10 & 12 & 14 & 16 \\
\hline \hline MAPE & 0.0227 & 0.0202 & 0.0098 & 0.0208 & 0.0257 & 0.0250 & 0.0245 \\
\hline MSE & 2.6441 & 1.9725 & 0.4770 & 2.1228 & 3.0375 & 3.0470 & 3.6003 \\
\hline
\end{tabular}


analysis and processing, discrete wavelet transform (DWT) has been developing rapidly. The discrete transform wavelet transform is defined as:

$W T_{j, k}=\int_{-\infty}^{\infty} f(t) \Psi_{j, k}(t) d t$

where: $j=0,1,2, \ldots ; k \in Z ; f(t)$ is the subject signal; $\Psi_{j, k}(t)$ is the wavelet function.

The approximation coefficient of the data $f(t)$ is denoted as:

$a_{j, k}=\int_{-\infty}^{\infty} f(t) \phi_{j, k}(t) d t$

where: $\phi_{j, k}(\mathrm{t})$ is the scaling function; $j$ and $k$ are scale and location, respectively.

For a range of scale $n$, the signal $f(t)$ can be expressed as:

$f(t)=f_{n}(t)+\sum_{j=1}^{n} d_{j}(t)$

where $f_{n}(t)$ denotes the mean signal approximation; $d_{j}(t)$ denotes the detail signal approximation in scale $j$.

Therefore, the wavelet transform decomposes a signal into two types of sub-signals: detail signals and approximation signals. Detail signals contain the upper part of the frequency components while approximation signals include the lower part.

\subsection{Correlation analysis between driving rhythm and driving comfort}

Driving rhythm represents large amounts of information during the driving process, so it should be decomposed into different levels in order to explore which part of driving rhythm is related to the driving comfort. Similar to music rhythm, driving rhythm also can be considered as a kind of signal. Hence, wavelet transform is used to analyze driving rhythm. To facilitate the calculation, the "music notes" of driving rhythm $\left(\frac{1}{\bullet}\right.$, $2, \ldots, \dot{7}$ ) are assigned a value from 1 to 21 respectively. Acceleration noise e is chosen as the driving comfort index to calibrating model, which can be calculated according to Equations 1-2. There are 790 valid samples employed for analysing. A 5-level wavelet transform of driving rhythm has been processed with the wavelet basic function Daubechies (db3). It consists of 5-scale details of the signal $d_{1}$ to $d_{5}$ and an approximation of the signal $a_{5}$. These signals represent different information of the wavelet transform of driving rhythm, so in this paper we want to find which signal is related to driving comfort. Figure 5 shows the wavelet transform of one road secti43on including 168 sets of data. It presents the detailed form of analysis results of a 5-level wavelet transform, including an approximation signal and detailed signals in scale levels 1-5.
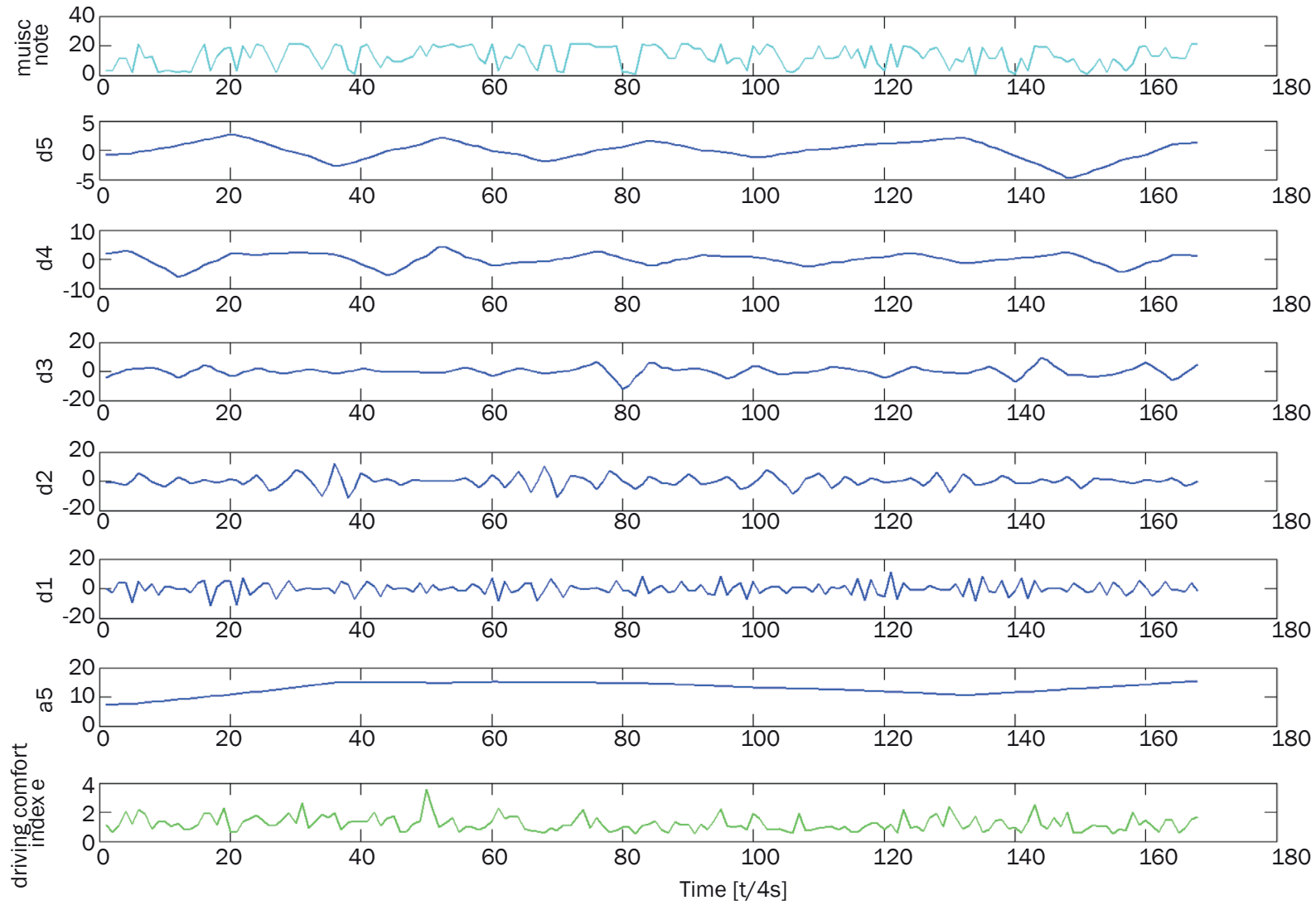

Figure 5 - Example of wavelet transform of driving rhythm on rural highways 
The test results of correlation analysis between wavelets and driving comfort are demonstrated in Table 4 . It can be seen that only $d_{5}$ is significantly related to driving comfort (Sig. <0.05), while the remaining wavelets have no significant correlation.

On the basis of acceleration noise, the driving comfort is split into three levels: "Good", "Fair" and "Bad". There are 201 samples pertaining to "Bad" driving comfort, accounting for $28.6 \%$ of the total, illustrated in Table 5. It indicates that driving comfort on rural highways is a severe problem. As shown in Figure 6, the probability density distribution of $d_{5}$ in each level obeys normal distribution. Distribution parameters and the results of Kolmogorov-Smirnov (K-S) test are listed in Table 5. It can be seen that all of three distributions pass K-S test (Asymp.Sig.>0.05), indicating that they all obey normal distribution. Moreover, the mean value of $d_{5}$ goes up with the decrease of the driving comfort. Then the probabilities of three levels of driving comfort can be calculated as follows:

Table 4 - Correlation analysis between wavelets and driving comfort

\begin{tabular}{|c|c|c|c|c|c|c||}
\hline Wavelets & $\mathrm{a}_{5}$ & $\mathrm{~d}_{1}$ & $\mathrm{~d}_{2}$ & $\mathrm{~d}_{3}$ & $\mathrm{~d}_{4}$ & $\mathrm{~d}_{5}$ \\
\hline \hline Sig.(2-tailed) & 0.473 & 0.995 & 0.727 & 0.996 & 0.462 & 0.021 \\
\hline
\end{tabular}

Table 5 - Distribution parameters and Kolmogorov-Smirnov test

\begin{tabular}{||c|c|c|c|c||}
\hline \multirow{2}{*}{$d_{5}$} & \multicolumn{2}{|c|}{ Normal distribution parameters } & \multirow{2}{*}{$\begin{array}{c}\text { Sample sizes } \\
N\end{array}$} & $\begin{array}{c}\text { K-S test } \\
\text { Asymp. Sig. (2-tailed) }\end{array}$ \\
\cline { 2 - 5 } & $\mu$ & $\sigma$ & 130 & 0.762 \\
\hline \hline Good & -0.19 & 1.06 & 459 & 0.268 \\
\hline Fair & -0.06 & 1.03 & 201 & 0.103 \\
\hline Bad & 0.08 & 1.05 & \\
\hline
\end{tabular}
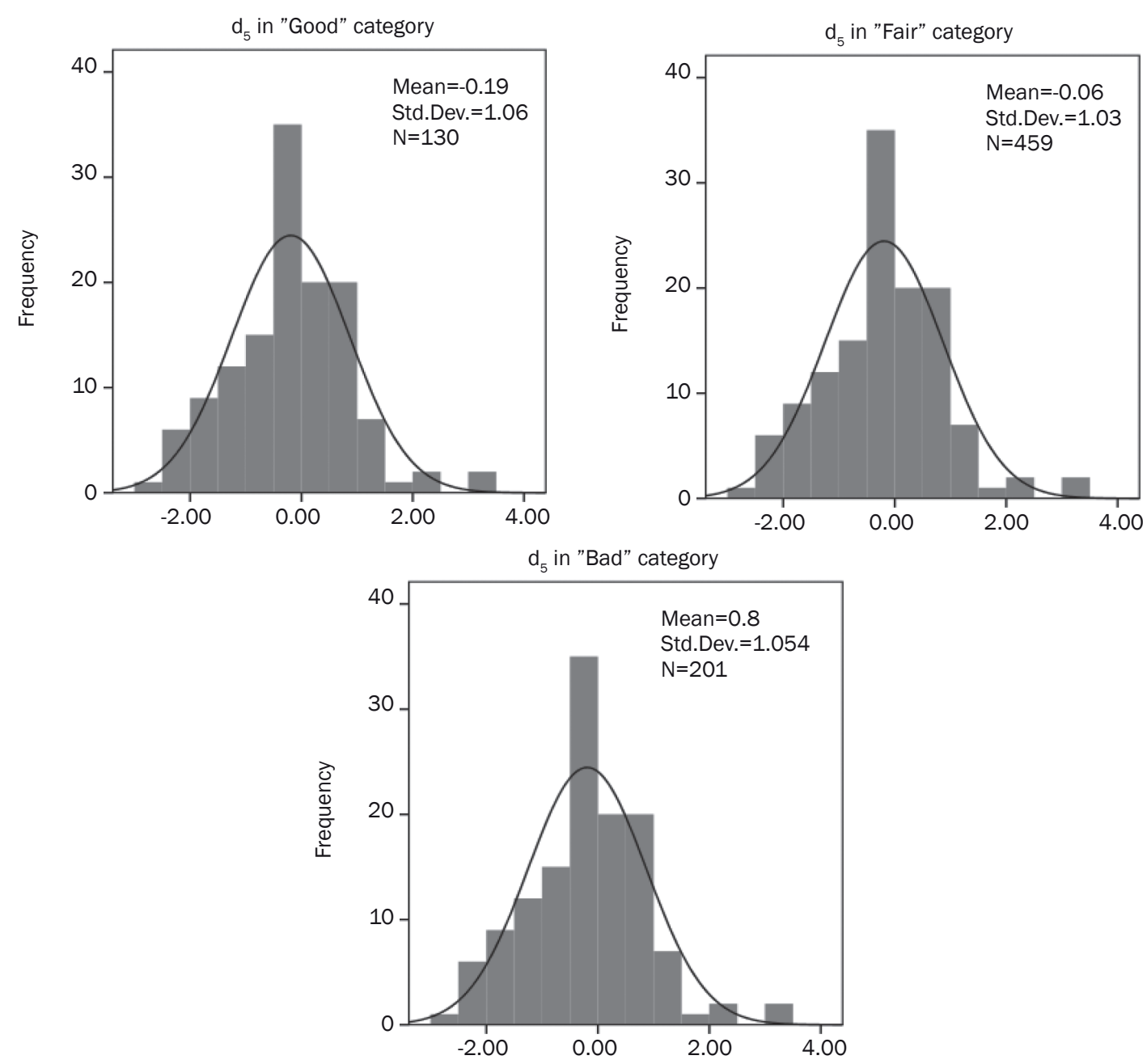

Figure 6 - Probability density distribution of $d_{5}$ in each level 


$$
\begin{aligned}
& f_{i}(x)=\frac{1}{\sqrt{2 \pi} \sigma_{i}} \exp \left(-\frac{\left(x-\mu_{i}\right)^{2}}{2 \sigma_{i}^{2}}\right) \\
& P_{i}=\frac{f_{i}(x)}{\sum_{j=1}^{3} f_{j}(x)}
\end{aligned}
$$

where: $i=1,2,3$, which means good, fair and bad driving comfort, respectively; $f_{i}(x)$ is the value of the probability density; $\mu_{i}, \sigma_{i}$ are the mean and variance, respectively, shown in Table 5; $P_{i}$ denotes the probability of driving comfort in i level.

\section{CONCLUSIONS}

The aim of this paper is to analyse the driving comfort on rural highways by the driver's visual perception. The driver's visual lane model was established based on the Catmull-Rom spline, in order to describe the information perceived by the driver's vision. Shape parameters of the visual lane model were put forward, which are $\left[v S_{L j(j+1)}, v K_{L j(j+1)}, v S_{R j(j+1)}, v K_{R j(j+1)}, v D_{j(j+1)}\right]$, representing the length, curvature and width of a lane in the driver's vision. The driving rhythm is the tempo at which the drivers perceive road conditions and then generate driving behaviour responses, indicating large amounts of information during the driving process. According to characteristic variables $\overline{\Delta V}$ and $\sigma^{2} / L$, the driving rhythm could be expressed as "music notes". Shape parameters of the driver's visual lane model were chosen as input variables to forecast the driving rhythm by BP neural network. Wavelet transform was used to explore which part of driving rhythm is related to driving comfort. Results showed that $d_{5}$ which refers to the detail signal in scale level 5 has a significant correlation with the driving rhythm. Driving comfort was split into three levels: "Good", "Fair" and "Bad". The probability density distribution of $d_{5}$ in each level obeys normal distribution. Then the probabilities of three levels of driving comfort could be calculated by wavelets of the driving rhythm.

This research not only provides a new perspective into driving comfort analysis and quantifies the driver's visual perception, but also gives attention to the unique characteristics of rural highways. Findings in this research can make a contribution to the optimization of rural highway design and improvement of driving comfort from driver's visual perception. The driving rhythm can depict the relationship between visual perception and physical sensation, and promote the harmony of people, vehicles, road and environment. Besides, the driver's visual lane model can help auxiliary driving technology perceive rural highways from the perspective of the driver. Next, we will further study the driver's behaviour characteristics and visual demands on rural highways, hoping to understand rural highway design in a better way.

\section{ACKNOWLEDGEMENT}

The authors acknowledge the support from the National Science Foundation of China (51078270, $51238008)$ and the Ministry of Education of China(20120072110019).

第一作者：余 博 (1993-), 男, 博士生, 道路与交 通工程教育部重点实验室, 同济大学交通运输工程 学院，中国上海市嘉定区曹安公路4800号，201804, 主要研究方向为道路交通安全与驾驶行为. E-mail: clowyubo@126.com

通讯作者：陈雨人 (1966一), 男, 教授, 博士生导师, 工学博士，道路与交通工程教育部重点实验室，同 济大学交通运输工程学院, 中国上海市嘉定区曹安 公路4800号，201804，主要研究方向为道路交通规 划设计、交通安全与道路环境、道路交通计算机辅 助工程. E-mail: chenyr@tongji.edu. cn

\section{基于驾驶韵律方法的农村公路行车舒适分析 摘要}

由于农村公路的行车速度变化特征相对复杂, 因 此行车舒适性的好坏对于农村公路意义重大。现有 关于行车舒适性的研究通常是基于实际的道路线形 和车辆特征两个方面, 几乎没有考虑驾驶人的视觉 感知, 但有学者指出驾驶人感知的道路线形与实际 的道路线形之间存在偏差, 尤其是对农村公路这类 对线形指标要求较低的道路, 此外很少有研究将农 村公路特性考虑其中。因此, 本文建立了基于Catmu11-Rom样条曲线的视觉车道模型来量化驾驶人在 农村公路的视觉感知, 采集了 $100 \mathrm{~km}$ 西藏地区农村公 路的实车实验数据, 并提出驾驶韵律来表征行车过 程中的驾驶信息, 将驾驶人视觉车道模型的形状参 数作为指标基于 BP神经网络建立了驾驶韵律的预测 模型, 同时采用了小波变化探索驾驶韵律中与行车 舒适性相关的组成成分, 并得到行车舒适性评价的 概率分布的计算方法。本研究不仅提供了行车舒适 性分析的新角度以及量化了驾驶人视觉感知, 同时 融入了农村公路的特征分析。

\section{关键词}

行车舒适性; 驾驶人视觉车道模型; 驾驶韵律; BP 神经网络; 小波变换;

\section{REFERENCES}

[1] Hassan Y, Sarhan M. Operational effects of drivers' misperception of horizontal curvature. Journal of Transportation Engineering. 2012;138(11):1314-1320.

[2] Gårder P. Segment characteristics and severity of head-on crashes on two-lane rural highways in Maine. Accident Analysis \& Prevention. 2006;38(4):652-661.

[3] Kashani AT, Mohaymany AS. Analysis of the traffic injury severity on two-lane, two-way rural roads based on classification tree models. Safety Science. 2011;49(10):1314-1320.

[4] Traffic Management Bureau of Ministry of Public Security. 2014 Road Traffic Accident Statistics Report PRC; 2015. 
[5] Yang Y, Ren W, Chen L, et al. Study on ride comfort of tractor with tandem suspension based on multi-body system dynamics. Applied Mathematical Modelling. 2009;33(1):11-33.

[6] Gao H, Sun W, Shi P. Robust sampled-data control for vehicle active suspension systems. IEEE Transactions on Control Systems Technology. 2010;18(1):238-245.

[7] Els PS, Theron NJ, Uys PE, et al. The ride comfort vs. handling compromise for off-road vehicles. Journal of Terramechanics, 2007;44(4):303-317.

[8] Múčka P, Granlund J. Is the road quality still better?. Journal of Transportation Engineering. 2012;138(12):1520-1529.

[9] Mayora JMP, Piña RJ. An assessment of the skid resistance effect on traffic safety under wet-pavement conditions. Accident Analysis \& Prevention. 2009;41(4):881-886.

[10] Awadallah F. Theoretical analysis for horizontal curves based on actual discomfort speed. Journal of transportation engineering. 2005;131(11):843-850.

[11] Els PS. The applicability of ride comfort standards to off-road vehicles. Journal of Terramechanics. 2005;42(1):47-64.

[12] Fwa TF, Chan WT, Sim YP. Optimal vertical alignment analysis for highway design. Journal of transportation engineering. 2002;128(5):395-402.

[13] Hamdar SH, Qin L, Talebpour A. Weather and road geometry impact on longitudinal driving behavior: Exploratory analysis using an empirically supported acceleration modeling framework. Transportation Research Part C: Emerging Technologies. 2016;67:193-213.

[14] Baykal O. Concept of lateral change of acceleration. Journal of Surveying Engineering. 1996;122(3):132-141.

[15] Yang S, Xu J, Yang Z, Pan B. The lateral change of acceleration in evaluation and control of highway design. Journal of Xi'an Highway University. 2001;21(1):46-48.

[16] Yu B, Chen Y. Driving Comfort Evaluation of Urban Road from Driver's Visual Perception. 15th COTA International Conference of Transportation Professionals; 2015.

[17] Ko J, Guensler R, Hunter M. Analysis of effects of driver/ vehicle characteristics on acceleration noise using GPSequipped vehicles. Transportation research part F: Traffic Psychology and Behaviour. 2010;13(1):21-31.
[18] Greenwood ID, Dunn RC, Raine RR. Estimating the effects of traffic congestion on fuel consumption and vehicle emissions based on acceleration noise. Journal of Transportation Engineering. 2007;133(2): 96-104.

[19] Hassan Y, Sayed T, Bidulka S. Influence of vertical alignment on horizontal curve perception: Phase II: Modeling perceived radius. Transportation Research Record: Journal of the Transportation Research Board. 2002;1796:24-34.

[20] Hassan Y, Easa SM. Effect of vertical alignment on driver perception of horizontal curves. Journal of transportation engineering. 2003;129(4):399-407.

[21] Wang $Y$, Shen D, Teoh EK. Lane detection using spline model. Pattern Recognition Letters. 2000;21(8):677-689.

[22] Summala $\mathrm{H}$. Latencies in vehicle steering: experimental studies on drivers' behavior on the road. No. B2 1981 Monograph; 1981.

[23] Zhao K, Meuter M, Nunn C, et al. A novel multi-lane detection and tracking system. Intelligent Vehicles Symposium (IV), 2012 IEEE. IEEE; 2012. p. 1084-1089.

[24] Yu B, Chen Y, Wang R, et al. Safety reliability evaluation when vehicles turn right from urban major roads onto minor ones based on driver's visual perception. Accident Analysis \& Prevention. 2016;95(Pt B):487-494.

[25] Chen Y, Yu B, He S. Coordination between highway horizontal and vertical alignments based on driver's visual perception deviation. Journal of Tongji University (Natural Science). 2015;43(9):1347-1354.

[26] Kamarianakis $Y$, Vouton V. Forecasting traffic flow conditions in an urban network: comparison of multivariate and univariate approaches. Transportation Research Record. 2003;1857(1):74-84.

[27] Zeng Q, Huang H. A stable and optimized neural network model for crash injury severity prediction. Accident Analysis \& Prevention, 2014;73:351-358.

[28] Pal S, Mitra M. Detection of ECG characteristic points using multiresolution wavelet analysis based selective coefficient method. Measurement. 2010;43(2):255-261.

[29] Zhu K, Wong YS, Hong GS. Wavelet analysis of sensor signals for tool condition monitoring: a review and some new results. International Journal of Machine Tools and Manufacture. 2009;49(7):537-553. 